\title{
THE EFFECT OF TYPE OF MATERIAL AND METHOD OF CONSTRUCTION ON THE FRACTURE TOUGHNESS OF DIFFERENT COMMERCIALLY AVAILABLE PROVISIONAL RESTORATION RESINS
}

\author{
Mohamed Medhat El Sayed Shrif*
}

\begin{abstract}
Purpose : to assess the most suitable resin restoration and methods of construction according to the fracture toughness as a provisional restoration among Bis-acryl resin (self-cure), RubberizedUrethane resin (dual cure), CAD/CAM PMMA (VITA CAD-Temp), CAD/CAM PMMA (breCAM. multiCOM).
\end{abstract}

Methods: A total of 40 specimens were constructed for this in vitro study. The specimens were divided into 2 groups according to the method of construction; manually fabricated group (M) and CAD/CAM group (C) ( $\mathrm{n}=20$ for each group). A split mold was specifically constructed for this in vitro study. The mold was constructed from Teflon material. The speciments of each group were prepared with dimensions ( $3 \times 4 \times 14)$ mm A notch was milled in the middle of each specimen by microsaw machine. The 3 -point bending test was carried out using universal testing machine (loud cell $500 \mathrm{~N}$ ). The fracture toughness data of each type of provisional material was tabulated and analyzed. The fractured surface morphology was captured using Scanning Electron Microscope (SEM).

Results: The 4 products were compared using ANOVA test. The greatest mean was recorded in breCAM.multiCOM group (B) $(1.074 \pm 0.195)$, whereas the lowest mean was recorded in TuffTemp group (T) $(0.6437 \pm 0.167)$. Tukey's post hoc test revealed no significant difference between Protemp 4 group (P), VITA CAD Temp group (V) and breCAM.multiCOM group (B). These 3 groups recorded significantly higher mean values in comparison to Tuff Temp group (T) CAD/CAM group (C) (1.0134 \pm 0.157$)$ recorded higher mean value the manual group (M) $(0.8459 \pm 0.275)$. The difference between the 2 construction methods was statistically significant $(\mathrm{P}=0.025)$

Conclusion: the first part of the null hypothesis was rejected because not all products recorded significantly different fracture toughness mean values. Also the second part of the null hypothesis was rejected because not all CAD/CAM provisional crowns demonstrated superior fracture toughness to that of conventional provisional materials.

KEYWORD: provisional restoration, Tuff-temp, Protemp

* Assistance Lecturer, Department of Fixed Prothodontics,Modern University For Technology and Information, Cairo Egypt 


\section{INTRODUCTION}

Fixed prosthodontic treatment needs indirect construction of the definitive prosthesis in the dental laboratory. While the definite prosthesis fabrication has been finished, a provisional restoration is necessary simulating the definite restoration in the shape and position. The requirements for satisfactory provisional restorations differ only slightly from the definitive treatment they precede.

Long-term provisional restoration is used in long term Extensive prosthodontic treatment, such as Occlual vertical dimension raising, alveoloplasty, tissue augmentation, dental implant, and orthodontics.

The importance of provisional restoration material requirements varies according to the Specific clinical treatments that the material is used for. For instance, the esthetic requirement is very important in anterior esthetic rehabilitation than posterior rehabilitation. Also provisional materials used in malocclusion correction and vertical dimension raising case must have high mechanical properties. ${ }^{1,2}$ The cases that need long term provisional restorations as implant cases, need durable provisional materials because of longer period of service.

\section{MATERIAL AND METHODS:}

A total of 40 specimens were constructed for this in vitro study. The specimens were divided into 2 groups according to the method of construction; manually fabricated group (M) and CAD/CAM group (C) (n=20 for each group). Each group was subdivided to 2 subgroups according to the type of the material; Protemp 4 group (P) , Tuff Temp group (T) , VITA CAD Temp group ( V) and breCAM. multiCOM group (B) (n=10 for each subgroup). The temporary crown material had been used in this study:

1. Protemp 4:- bis-acrylic material with nanofillers for the fabrication of single- and multiple-unit crowns, bridges, inlays/on lays and veneers, including long-term provisional restorations. Shade (A2).

2. Tuff Temp:-diurethane dimethacrylate resin material in which synthetic hydrogenated polybutadine rubber molecules have been inserted.

3. VITA CAD Temp:-CAD /CAM block provisional resin material which consists of a fiberfree, high-molecular and cross-linked acrylate polymer MRP (Micro-filler Reinforced Polyacrylic)

4. breCAM.multiCOM:- CAD /CAM provisional resin material disk which its manufacture based on polymethyl methacrylate and has been offset with $>20 \%$ ceramic filers.

A split mold was specifically constructed for this in vitro study. The mold was constructed from (Teflon) material. The mold had cuboid geometry with dimensions (40 x $30 \times 25 \mathrm{~mm})\{$ fig 1$\}$, which was split to two parts. The mold was milled by a lathe machine. The two Teflon parts were connected together by two metal bars with two screws on their ends, used in separating and assembling the Teflon parts by winding and unwinding movement to facilitate removal of the specimen from the mold after fabrication. The mold has a cuboid space (dimensions $3.0 \times 4.0 \times 14 \mathrm{~mm}$ ) in which the manually fabricated provisional restoration materials (Protemp 4 and Tuff Temp) were poured to construct specimens with these dimensions. After pouring the specimen, the screws was unwind then the two parts were separated then the specimen removed easily from the mold space. ${ }^{3-5}$

The Protemp 4 cartilage was loaded in a special dispenser gun (3M ESPE, Garant ${ }^{\mathrm{TM}}$ Dispenser 4:1/10:1 ratio) The Tuff Temp specimens were prepared in a similar manner as Protemp 4 specimens. But the difference was that tuff temp was loaded in another special dispenser gun ((AcumixAutomix Cartridge Dispensing Gun, 1:1 / 2:1 ratio). 
VITA CAD Temp block with size (15.5 x 19 x $55 \mathrm{~mm}$ ) code (CT-55) was milled by microsaw machine, using $0.5 \mathrm{~mm}$ thickness diamond disk, with rotation speed $2500 \mathrm{rpm}$ and feeding rate $1 \mathrm{~mm} / \mathrm{s}$, with cooling water spray. A cuboid sheet was cut from the complete block with dimensions (4 x $14 \times 50)$ mm.A breCAM. multiCOM disk with dimensions ( $98.5 \mathrm{~mm}$ diameter $\mathrm{x} 16 \mathrm{~mm}$ thickness), code (540 03010 ), was milled using the same microsaw machine with the same diamond disk type and milling speed(diamond disk Buehler USA).

The final CAD/CAM specimens' preparation the sectioned sheets were farther milled to obtain 10 specimens for each group with dimensions $(3 \mathrm{x}$ $4 \times 14) \mathrm{mm}$. A notch was milled in the middle of each specimen by microsaw machine (Isomet 4000 microsaw Buehler USA), using $0.35 \mathrm{~mm}$ thickness diamond disk (diamond disk Buehler USA), with rotation speed $2500 \mathrm{rpm}$ and feeding rate $1 \mathrm{~mm} / \mathrm{s}$, with cooling water spray. ${ }^{6}$

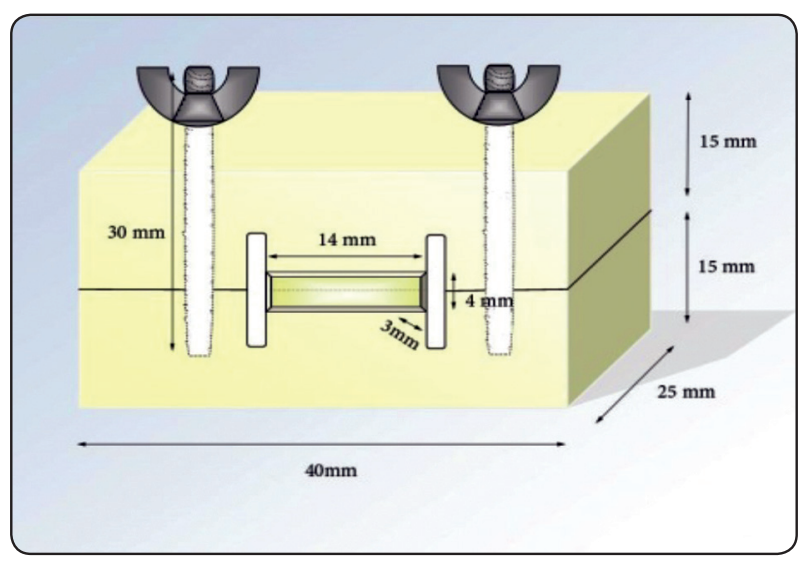

Fig (1): A split mold with cuboid geometry with dimensions (40 x $30 \times 25 \mathrm{~mm}$ )

The crack was imaged using stereomicroscope (Omnimet image analysis software Buehler USA) at 50x magnification, and the accurate crack length value for each specimen was measured by image analysis software (Instron Universal Testing machine model 3345 England) and recorded.
The 3-point bending test was carried out using universal testing machine (loud cell $500 \mathrm{~N}$ ). The data were recorded using special software (Bluehill Lite software version 3.3), to determine the peak "force to fracture" for each specimen. ${ }^{7,8}$

The peak "force to fracture" in Newton was derived from the stress-strain curve and recorded. This force was used to calculate the fracture toughness (K1c) in $\mathrm{MPa} \bullet \mathrm{m} 1 / 2$. The fracture toughness data of each type of provisional material was tabulated and analyzed. The fractured surface morphology was captured using Scanning Electron Microscope (Quanta ${ }^{\mathrm{TM}}$ FEG250 - Scanning Electron Microscope) at an accelerating voltage of $20 \mathrm{kV}$ and a magnification of 2000-20000x. The specimens were sputtered with gold prior to scanning.

\section{RESULTS:}

The 4 products were compared using ANOVA test. The greatest mean was recorded in breCAM. multiCOM group (B) $(1.074 \pm 0.195)$, whereas the lowest mean was recorded in Tuff-Temp group (T) $(0.6437 \pm 0.167)$. The difference between the four groups was statistically significant $(\mathrm{P}<0.0001)$. The 2 products within the same construction method were compared using unpaired $t$ test. Within the manual group (M), the Protemp 4group (P) (1.048 \pm 0.203$)$, recorded higher mean value than TuffTemp group (T) $(0.6437 \pm 0.167)$. The difference between the 2 products was statistically significant $(\mathrm{P}<0.0001)$ $\{$ fig 2$\}$.

Within the CAD/ CAM group (C), breCAM. multiCOMgroup(B) (1.074 \pm 0.195$), \quad$ recorded higher mean value than Vita CAD Temp group (V) $(0.9528 \pm 0.077)$. The difference between the 2 products was not statistically significant $(\mathrm{P}=0.094)$. \{Fig 3\}.

To study the effect of method of construction difference, the 2 methods were compared using unpaired t test.CAD/CAM group (C) (1.0134 \pm 0.157$)$ recorded higher mean value the manual group (M) 


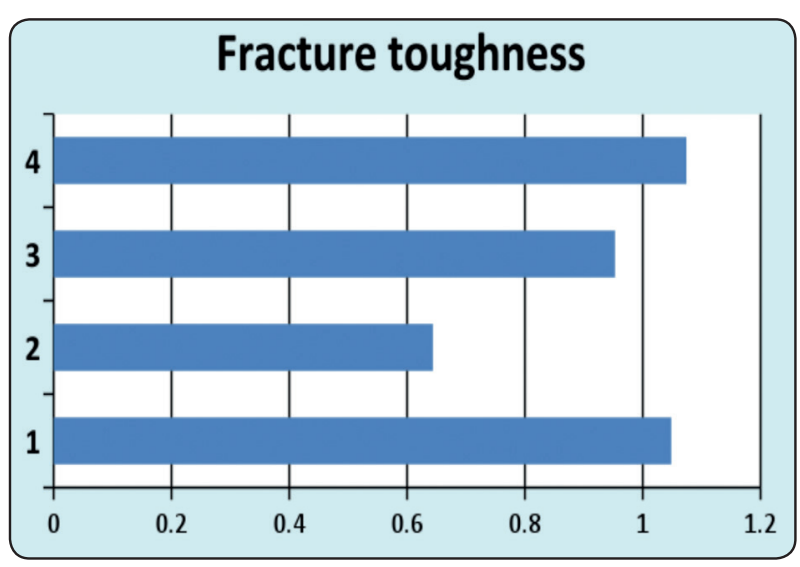

Fig. (2): Column chart showing difference of mean fracture toughness test in different products within each construction method.

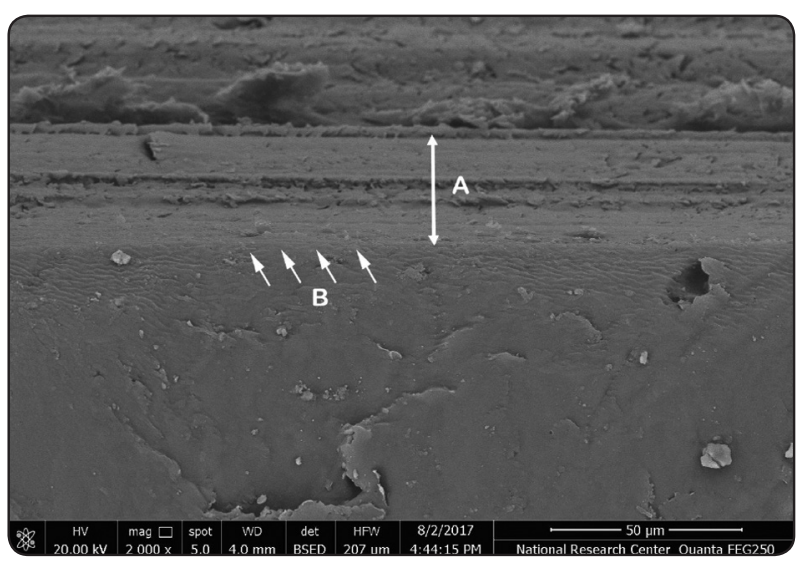

Fig (4): Cracks under scan electric microscope

$(0.8459 \pm 0.275)$. The difference between the 2 construction methods was statistically significant $(\mathrm{P}=0.025)$

\section{SEM analysis}

It showed the pre-crack zone (arrow A) and the transition line between the pre-crack button and the beginning of fractured surface (arrows B). \{Fig 4\}

In Protemp 4 specimens $(\mathrm{P})$, showed fracture surface with step form configuration with river like structure which is a typical morphology of brittle fracture through cleavage $\{$ Fig 4$\}$. The surface shows no porosities or filler matrix disintegration.

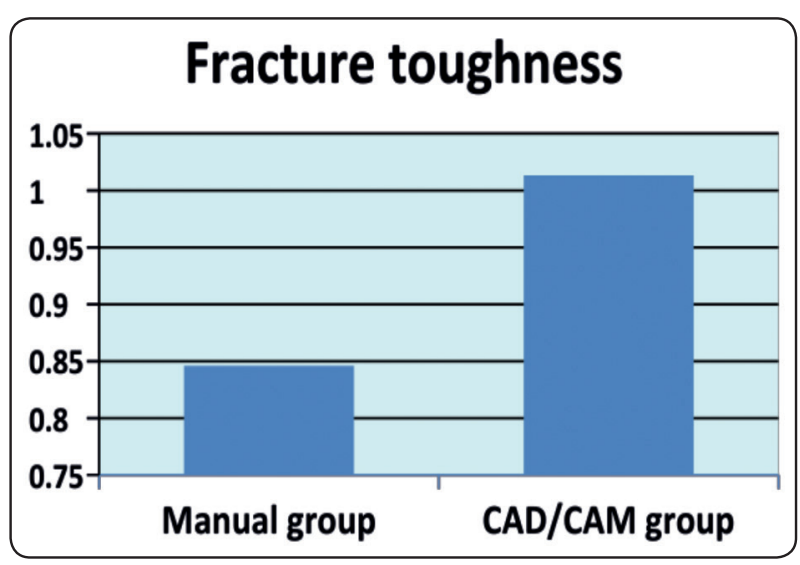

Fig. (3): Column chart showing difference of mean fracture toughness test in different products within each construction method.

In Tuff Temp specimens (T), showed the fracture surface with smooth fracture pattern without step form brittle fracture configuration but with porous surface and microcracks. The magnification of the synthetic rubber molecule showed partial disintegration of the molecules from the matrix. In VITA CAD Temp specimens (V), showed step form brittle fracture configuration with intimate contact between polymer beads and the resin matrix without surface porosity or any evidence of disintegration.

\section{DISCUSSION}

In the present study, a comparison of the fracture toughness of different provisional restoration resins was done to study the effect of the type of the material and method of construction on their mechanical behaviour. While this in vitro study may not reflect the oral conditions, fracture toughness values could be a useful predictor of clinical performance and helpful for comparing provisional materials tested in a controlled situation. Bis-acryl composite resins have low exothermic reaction, low polymerization shrinkage , ${ }^{9-12}$ good wear resistance, and good strength; but, these materials are expensive, brittle, have less polished surface 15 and their repair is difficult.$^{16,17}$ The addition of nanofillers was claimed to provide a smooth surface after the polishing process and provide superior 
esthetic features to the material. The composite resin materials which have this particle size have high strength, malleability and abrasion resistant quality ${ }^{18}$. In this study, a bisacryle provisional resin material was tested which was based on a combination of nanofillers and polymers that work together. The effect of bisacryle composition was tested and nanotechnology on the fracture toughness in comparison to the other materials.

Another type of provisional resin materials is urethane dimethacrylates. Urethane dimethacrylates have controllable working time, good wear resistance, low temperature changes, good color stability and high fracture toughness. ${ }^{19,20}$ The synthetic rubber particles were claimed to improve Urethane dimethacrylates mechanical properties, specially its fracture toughness to be used as a long term provisional resin restoration. ${ }^{21}$

AnUrethane dimethacrylate provisional resin material was tested in this study which was strengthened by adding synthetic rubber particles to evaluate the effect of the Urethane dimethacrylate composition and the addition of synthetic rubber particles on the fracture toughness when compared with the other tested materials. PMMA material provisionalresins is relatively inexpensive, with good color stability, excellent polished surface, and good marginal adaptation..$^{22}$ The major drawbacks of this group of resins include, high polymerization shrinkage ${ }^{15,21}$, low strength, wear resistance, and exothermic polymerization which may cause pulpal irritation associated with excess free monomer. ${ }^{18-24}$ $\mathrm{CAD} / \mathrm{CAM}$ technology was used to fabricate temporary restorations as a trial to solve some of these problems by the way of curing using resin based blanks under optimal conditions to increase their mechanical strength and prevent porosities within the restorations. ${ }^{25}$ In addition, CAD/CAM fabricated provisional materials reduce the chairside time and produce superior results. ${ }^{27}$ So we tested a poly methyl methaacrylate (PMMA) provisional resin material which was manufactured in the form of CAD/ CAM blocks to evaluate the effect of method of construction modifying on the fracture toughness of the provisional materials.

The last tested material was another representative of PMMA which is in the form of CAD/CAM disks in addition to $20 \%$ ceramic fillers to improve its mechanical properties specially the fracture toughness. ${ }^{28}$ So we tested this material to evaluate the effect of $\mathrm{CAD} / \mathrm{CAM}$ manufacturing technique and farther addition of $20 \%$ ceramics fillers on its fracture toughness.

There are variable methods were used in testing the fracture toughness of provisional resin materials. These tests include three- point bending, four-point bending ${ }^{29}$ with single-edge notched beam ${ }^{30}$ chevron notch, compact tension 31 and the indentation hardness method ${ }^{31}$ specimens' configuration. All these methods gives a range of fracture toughness (KIc) values, even for the same material. ${ }^{29}$ These methods differ on its tested specimen geometry in the size and the shape, size of the crack, and loading configuration.

The complexity of the subjected forces to the provisional restoration in the oral cavity makes the suitable method selection for testing the fracture toughness isn't easy. So many studies have attempted to establish some clinically reliable testing methods for measuring the fracture toughness of the provisional resin materials ${ }^{32-34}$ The single edge notched beam (SENB) is from the most reported reliable methods which have been used in fracture toughness testing standard, ISO $6872 .{ }^{35}$ The singleedge-notched beam (SENB) is suggested for dental materials, because this test requires a smaller specimen size to fulfil plane strain conditions as compared to configurations of specimens of other tests. So we used the single edge notched beam (SENB) as a fracture toughness testing method to compare the fracture toughness of the 4 tested materials.

The specimens were fabricated in the form of bars with dimensions of ( $3.0 \times 4.0 \times 14 \mathrm{~mm})$ according to ISO $6872^{36}$ modified to accommodate block sizes that the specimens were sectioned from ${ }^{37}$. 
The improved processibility is another advantage In addition to its hydrophobicity, and low adhesive forces.

The aim of mold constructing in the form of split mold with metal screws is to easily seperate and assembles its two parts by unwending and rewending the screws to help removing the spacimens from the mold space easily.

After pouring the specemens, a glass slab was then seated over the mold to pack the mix and to help removing the excess material. The specimens were allowed to polymerize for $7 \mathrm{~min}$ at room temperature as recommended by the product using instructions. Tuff Temp specimens group (T) was light cured for $20 \mathrm{sec}$. Because it is a dual cured resin material. The using of glass slab had 2 aims. The first was to avoid the air inhibited layer on the superficial surface of the specimen to allow complete and equal curing. The second aim was to standardize the distance between the light cure unit tip and the specimen to standardize the light curing measures between all the specimens. Surface Finishing affect the mechanical properties of the provisional materials so after the specimens were removed, a razor was used to remove all of the flash material and finished to the desired dimensions with 400 grit and 600 grit abrasive papers.

In The CAD/CAM fabricated provesional material specimens (C), we used Isomet 4000 microsaw in milling the specimens to standardize and control the sizes of the specimens. The process was done with rotation speed $2500 \mathrm{rpm}$ and feeding rate $1 \mathrm{~mm} / \mathrm{s}$ with cooling water spray. This machine is provided by cooling system (water) \& cool (anticorrosive agent) 30:1. The Integrated coolant delivery system floods the specimen from both sides of the blade while tracking with blade movement. This feature was suitable for the resin material used to avoid heating and destruction of the specimens. The machine has SmartCut system which monitors and adjusts feed rates to enhance surface quality and prevent damage to specimen or machine. Also the machine has the advantage of Linear feed mechanism with variable feed rate sections even the most delicate specimens so it suited the natural of the study delicate resin materials.

In metal testing, an initial machined notched sample is fatigued to give some growth. In polymeric materials, this method is often difficult to do because of unstable fatigue crack growth and the necessity of using low frequencies to avoid heating. In polymers another method is applied by first machining a sharp notch and then further sharpening it by using a razor blade. This is generally a much simpler technique than growing cracks in fatigue that suites the resin material delicate nature. Polymers are viscoelastic materials so it is recommended that feeding rate must never be exceed $1 \mathrm{~mm} / \mathrm{s}$ because of the danger of dynamic effects that may lead to errors. ${ }^{37}$ so the milling procedures were done under feeding rate1 $\mathrm{mm} / \mathrm{s}$.

A notch on the central was introduced in each specimen by Isomet 4000 microsaw Buehler USA machine. The specimens were milled with rotation speed $2500 \mathrm{rpm}$ and feeding rate $1 \mathrm{~mm} / \mathrm{s}$ with cooling water spray to avoid heating during the milling of the speciemens to the planned dimensions, and then a sharp pre-crack was introduced at the end of the notch by a sharp razor to make fine sharp cuts with average length $0.5 \mathrm{~mm}$. Most of studies recommended that the crack length (the notch + percrack) (a) should be: $0.45<\mathrm{a} / \mathrm{W}<0.55 .^{37,38}$ So the crack was fabricated with an average leghth of $2 \mathrm{~mm}$ to apply this rule.

The crack was imaged using MA 100 Nikon steriomicroscope Japan At 50x magnification and the crack length values were measured by Omnimet image analysis software Buehler USA to estimate the actual crack length of each specimens to use it in the fracture toughness equation according to ASTM E-399 to calculate the exact fracture toughness value of each spacemen.

The 3-point bending test was carried out. The main advantage of this test is the ease of the specimen 
preparation and testing. ${ }^{39}$ Instron Universal Testing machine was used with loud cell $500 \mathrm{~N}$ because the maximum biting forces is $100 \mathrm{~N}$ in anterior teeth and may reach to $500 \mathrm{~N}$ in the posterior teeth. ${ }^{40}$

The fracture pattern and the fracture surface morphology are important in studying the fracture toughness of the provisional resins. The fractured surface was captured using Scanning Electron Microscope at an accelerating voltage of $20 \mathrm{kV}$ and a magnification of $2000-20000 \times$ to study the morphological characterization of the fracture sites. The Magnification of 2000-20000 × was used to clearly investigate the fracture surface and material composition, matrix particles integration and porosity. The specimens were sputtered with gold prior to scanning. Sputter coating in scanning electron microscopy is a sputter deposition process to cover a specimen with a thin layer of conducting material, typically a metal, such as a gold/ palladium $(\mathrm{Au} / \mathrm{Pd})$ alloy. A conductive coating is needed to prevent charging of a specimen with an electron beam in conventional SEM mode (high vacuum, high voltage). While metal coatings are also useful for increasing signal to noise ratio (heavy metals are good secondary electron emitters. ${ }^{41}$

The null hypothesis of this study was that the type of the material and technique of construction affect the fracture toughness of the provisional restorations.

Tuff temp recorded significantly the lowest mean values in comparison to other products, showing that urethane dimethacrylate has lower mechanical properties than other provisional resin materials in this study. This was in agreement with a previous study showed that light activated Urethane Dimethacrylate Resin had the least flexural strength in comparison to the other types of the provisional resin materials. ${ }^{42}$ Tuff-Temp was claimed by the manufacturer to exhibit very high flexural strength without brittleness and Its far greater deflection at break; the key indicator of toughness, was greater than bis-acrylics including protemp $4 .{ }^{43}$ However other author ${ }^{35}$ compared the same products; Tuff temp with Protemp 4 and found superior mechanical properties were noted with the urethane resin (Tuff-Temp) 1 hour after fabrication and with a bis-acryl resin (Protemp 4) at 24 hours. Postgelation polymerization plays an important role in substantially increasing the flexural strength and rigidity of the bis-acryl and, to a lesser extent, urethane interim resins between 1 and 24 hours. SEM photographs in this study showed a porous less dense structure of tuff temp as well as partially separated rubbers particles appeared on the fracture surface in comparison to the other products. This may be another cause in its significant low fracture toughness value.

BreCAM.multicom and VITA CAD Temp are two examples of CAD/CAM fabricated provisional resin materials. Very little data exist in the literature regarding the mechanical prosperities of these modern provisional materials.BreCAM.multicom manufacture based on polymethyl methacrylate and has been offset with $>20 \%$ ceramic filers in order to increase the strength. The inorganic filler (ceramic particle) has been integrated in the plastic matrix of the organic PMMA. In this study BreCAM. multicom recorded higher fracture toughness mean value but without significant difference when was compared with VITA CAD Temp, in despite of adding $20 \%$ ceramic fillers to the PMMA in BreCAM.multicom. In this study SEM photographs showed a homogenous dense structure. However, micro voids were excited with the evidence of ceramic fillers matrix separation during fracture. It may be a cause in the insignificant effect of adding $20 \%$ ceramics. ${ }^{43}$

VITA CAD Temp consists of a fiber-free, homogeneous, high-molecular and cross-linked acrylate polymer with micro-particle filler, or MRP material. In the MRP material (Micro-filler Reinforced Polyacrylic) inorganic micro-fillers are polymerized into the network and a completely homogeneous, VITA CAD Temp was claimed that its methyl methacrylate-free material is obtained 
by the unique repressing technique of VITA, which exhibits superior material quality and outstanding abrasion resistance .Protemp 4 recorded the second highest fracture toughness mean value but without significant difference when compared with BreCAM. multicom and VITA CAD Temp. However, another study showed significant higher flexural strength of protemp 4 when compared with VITA CAD Temp1. the mechanical characteristics of Structure Premium (Voco), Protemp 4 Temporization Material, Acrytemp, Kanitemp Royal, Integrity Fluorescence and Luxatemp Fluorescence materials had compared ${ }^{44}$. They found that the fracture toughness of a Protemp 4 material was established to be the highest as compared to all others.

\section{CONCLUSION}

The first part of the null hypothesis was rejected because not all products recorded significantly different fracture toughness mean values. Also the second part of the null hypothesis was rejected because not all CAD/CAM provisional crowns demonstrated superior fracture toughness to that of conventional provisional material.

\section{REFRENCES}

1. Jain A R, Nallaswamy D, and Padma Ariga J: Full mouth rehabilitation of a patient with reduced vertical dimension using multiple metal ceramic restorations. Contemporary clinical dentistry, 2013.4(4): p. 531

2. Karakıs D, Kaymak D, and Dogan D: The evaluation of maximum bite force in the occlusal rehabilitation of patient with Angle Class III malocclusion: a case report. The journal of advanced prosthodontics, 2013. 5(3): p. 364-368.

3. Hammond B and Hodd $\mathbf{J}$ : Fiber-reinforced interim fixed dental prostheses: A clinical protocol. The Journal of Prosthetic Dentistry, 2016. 116(4): p. 496-500.

4. Anderson TL: Fracture Mechanics: Fundamentals and Applications, USA, 2005.3rd Ed.

5. Fahmy NZ and Sharawi A: Effect of two methods of reinforcement on the fracture strength of interim fixed partial dentures. Journal of Prosthodontics, 2009. 18(6): p. $512-520$.
6. Hamza, TA et al: The effect of fiber reinforcement on the fracture toughness and flexural strength of provisional restorative resins. The Journal of prosthetic dentistry, 2004. 91(3): p. 258-264.

7. Meiers, JC and Freilich MA: Use of a prefabricated fiberreinforced composite resin framework to provide a provisional fixed partial denture over an integrating implant: a clinical report. The Journal of prosthetic dentistry, 2006. 95(1): p. 14-18.

8. Baldissara P, Katsinas G , and Scotti R : Use of carbonepoxy frameworks for reinforcing provisional fixed partial dentures. The Journal of prosthetic dentistry, 2004. 91(1): p. 89-92.

9. Grajower R, Shaharbani S, and Kaufman E: Temperature rise in pulp chamber during fabrication of temporary selfcuring resin crowns. The Journal of prosthetic dentistry, 1979. 41(5): p. 535-540.

10. Manak E and Arora: A Comparative evaluation of temperature changes in the pulpal chamber during direct fabrication of provisional restorations: an in vitro study. The Journal of Indian Prosthodontic Society, 2011. 11(3): p. $149-155$

11. Kurtzman $\mathrm{G}$ : Crown and bridge temporization part 1: provisional materials. Inside Denistry, 2008. 4: p. 72-80.

12. Lieu C, Nguyen TM and Payant L : In vitro comparison of peak polymerization temperatures of 5 provisional restoration resins. Journal-canadian dental association, 2001. 67(1): p. 36-39.

13. Gegauff A and Holloway J: Interim fixed restorations. Contemporary Fixed Prosthodontics. 4th ed. Mosby Elsevier, 2006: p. 466-504.

14. Strassler $\mathrm{H}$, Anolik $\mathrm{C}$ and Frey $\mathrm{C}$ : High-strength, aesthetic provisional restorations using a bis-acryl composite. Dentistry today, 2007, 26(11): p. 128, 130.

15. Guler AU et al: Effects of different drinks on stainability of resin composite provisional restorative materials. The Journal of prosthetic dentistry, 2005 . 94(2): p. 118-124.

16. Bohnenkamp DM and Garcia LT: Repair of bis-acryl provisional restorations using flowable composite resin. The Journal of prosthetic dentistry, 2004. 92(5):p.500-502.

17. Blalock JS and Cooper J: A technique for effective shade modification of a provisional restoration. The Journal of prosthetic dentistry, 2011. 105(5): p. 347-348. 
18. Kumar SR and Vijayalakshmi R: Nanotechnology in dentistry. Indian J Dent Res, 2006. 17(2): p. 62-65.

19. Peutzfeldt A: Resin composites in dentistry: the monomer systems. European journal of oral sciences, 1997. 105(2): p. 97-116.

20. Beatty $M$ et al: Effect of cross linking agent content, monomer functionality, and repeat unit chemistry on properties of unfilled resins. Journal of biomedical materials research, 1993. 27(3): p. 403-413.

21. Lee V, Cardenas HL and Rawls HR: Rubber-toughening of dimethacrylate dental composite resin. Journal of Biomedical Materials Research Part B: Applied Biomaterials, 2010. 94(2): p. 447-454.

22. Hammond BD, COOPER JR and Lazarchik DA : Predictable repair of provisional restorations. Journal of Esthetic and Restorative Dentistry, 2009. 21(1): p. 19-24.

23. Burns DR, Beck D, and Nelson S K : A review of selected dental literature on contemporary provisional fixed prosthodontic treatment: report of the Committee on Research in Fixed Prosthodontics of the Academy of Fixed Prosthodontics. The Journal of prosthetic dentistry, 2003. 90(5): p. 474-497.

24. Balkenhol $\mathrm{M}$ et al: Correlation between polymerization shrinkage and marginal fit of temporary crowns. Dental materials, 2008. 24(11): p. 1575-1584.

25. Poticny DJ and Klim J: CAD/CAM in-office technology: innovations after 25 years for predictable, esthetic outcomes. The Journal of the American Dental Association, 2010. 141: p. 5S-9S.

26 Gougaloff R and Stalley FC: Immediate placement and provisionalization of a dental implant utilizing the CEREC 3 CAD/CAM Protocol: a clinical case report. Journal of the California Dental Association, 2010 . 38(3): p. 170-3, 176-7.

27. Alhareb A, Akil HM, and Ahmad Z A: Impact strength, fracture toughness and hardness improvement of PMMA denture base through addition of nitrile rubber/ceramic fillers. The Saudi Journal for Dental Research, 2017.8(1): p. 26-34.

28. Ferooz $\mathrm{M}$ et al: The Role of home bleaching agent on the fracture toughness of resin composites using four-point bending test. Journal of Dental Biomaterials, 2014. 1(1): p. 9-15.

29. Wang $\mathrm{H}$ et al: Fracture toughness comparison of three test methods with four dental porcelains. Dental materials, 2007. 23(7): p. 905-910.
30. Bagheri $\mathrm{R}$ et al: Effect of a home bleaching agent on the fracture toughness of resin composites, using short rod design. Journal of Dentistry, 2014. 15(2): p. 74.

31. Fischer $\mathrm{H}$ and Marx R: Fracture toughness of dental ceramics: comparison of bending and indentation method. Dental materials, 2002. 18(1): p. 12-19.

32. Watanabe $\mathrm{H}$ et al: Fracture toughness comparison of six resin composites. Dental materials , 2008. 24(3): p. 418425 .

33. Fujishima A and Ferracane JL, Comparison of four modes of fracture toughness testing for dental composites. Dental Materials, 1996. 12(1): p. 38-43.

34. Triwatana, P, Srinuan $\mathrm{P}$, and Suputtamongkol K, Comparison of two fracture toughness testing methods using a glass-infiltrated and a zirconia dental ceramic. The journal of advanced prosthodontics, 2013. 5(1): p. 36-43.

35. ISO 6872: 2008. Dentistry - Ceramic materials, r.e., G. International Organization for Standardization, and 2008.

36. Norman $\mathrm{C}$ et al: Fracture toughness of a new resin nanoceramic CAD/CAM material. In Abstract\# 639, Annual Meeting of the AADR. 2012.

37. Williams $\mathbf{J}$ and Cawood M: European group on fracture: Kc and Gc methods for polymers. Polymer testing, 1990. 9(1): p. 15-26.

38. Garoushi S, Vallittu PK and Lassila LV : Fracture toughness, compressive strength and load-bearing capacity of short glass fibre-reinforced composite resin. Chinese Journal of Dental Research, 2011. 14(1): p. 15.

39. Rao MA et al: Engineering properties of foods. 2014: CRC Press.

40. Zhou Z et al : Dental biotribology. 2013: Springer.

41. Newbery D et al: Advanced Scanning Electron Microscopy and X-Ray Microanalysis. Plenum Press. ISBN 0-30642140-2. (1986).

42. Kadiyala K et al: Evaluation of Flexural Strength of Thermocycled Interim Resin Materials Used in Prosthetic Rehabilitation-An In-vitro Study. Journal of clinical and diagnostic research: JCDR, 2016. 10(9): p. ZC91.

43. Vita-zahnfabrik: Working instructions. cited 2015 Oct. . Available from: https: https://www.vita-zahnfabrik. com/ pdb_cc3c49_en.html.

44. Abdullah AO, Tsitrou EA, and Pollington S: Comparative in vitro evaluation of $\mathrm{CAD} / \mathrm{CAM}$ vs conventional provisional crowns. Journal of Applied Oral Science, 2016. 24(3): p. 258-263. 